\title{
The effect of toothpastes with bleaching agents on the force decay of elastomeric orthodontic chains
}

\author{
Mohammad Behnaz ${ }^{1}$, Kazem Dalaie ${ }^{2}$, Sepanta Hosseinpour ${ }^{3}$, \\ Fatemeh Namvar ${ }^{2}$, Leila Kazemi ${ }^{4}$
}

Correspondence: Dr. Fatemeh Namvar Email: fatemehnamvar58@yahoo.com

\begin{abstract}
'Dental Research Center,Research Institute of Dental Sciences, School of Dentistry, Shahid Beheshti University of Medical Sciences, Tehran,Iran, 2Department of Orthodontics, School of Dentistry, Shahid Beheshti University of Medical Sciences, Tehran, Iran,

${ }^{3} \mathrm{DDS}, \mathrm{MPH}$, Research Fellow, School of Advanced Technologies in Medicine, Shahid Beheshti University of Medical Sciences, Tehran, Iran,

${ }^{4}$ Dentist, Tehran, Iran
\end{abstract}

\section{ABSTRACT}

Objective: The aim of this study was to evaluate the effect of agents available in whitening toothpastes (Crest ${ }^{\circledR}$ and Sensodyne $\left.{ }^{\circledR}\right)$ in vitro on the force decay of elastomeric chains used in orthodontics. Materials and Methods: A total of 300 specimens of elastomeric chains were divided into five groups $(n=60)$ and were evaluated. These groups included (1) the regular Crest ${ }^{\circledR}$ toothpaste and distilled water solution, (2) whitening Crest ${ }^{\circledR}$ toothpaste and distilled water solution, (3) regular Sensodyne ${ }^{\circledR}$ toothpaste and distilled water solution, (4) whitening Sensodyne ${ }^{\circledR}$ toothpaste and distilled water solution, and (5) distilled water as a control group. The samples' force was measured using Instron at intervals of 0, 1, 7, 14, 21, and 28 days. Data were analyzed by SPSS software. Results: At the initial time point, the difference in the force values of elastomeric chain between any of the groups was not significant $(P>0.05)$. On the $1^{\text {st }}$ day, there was a significant difference $(P<0.05)$ between all groups except the groups of whitening Crest ${ }^{\circledR}$, regular, and whitening Sensodyne ${ }^{\circledR}(P>0.05)$. On days 7,14 , and 28 , the rate of decline for all groups was statistically significant $(P<0.05)$. Conclusions: According to the results obtained in the present study, it seems that toothpastes without whitening agents have less effect on force decay of elastomeric chain over time.

Key words: Crest $^{\circledR}$, elastomeric chain, Sensodyne ${ }^{\circledR}$, tooth paste, whitening agent

\section{INTRODUCTION}

Elastomeric chains are one of the orthodontic force-exerting factors that are commonly used and have several advantages such as high flexibility and low price in comparison to other orthodontic approaches; ${ }^{[1-3]}$ also they do not require patient cooperation and are relatively hygienic. ${ }^{[4]}$ The elastomeric chains can be used for canine retraction. Elastic appliances are

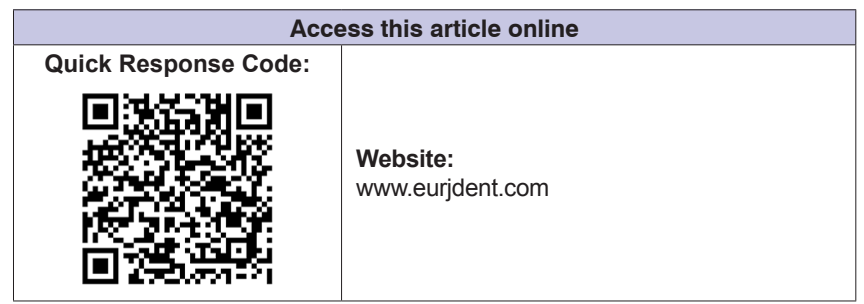

made of latex and patients are required to replace them every day. ${ }^{[5,6]}$ Despite the numerous advantages of elastomeric chains over latex appliances, there are always concerns about their force decay. These chains are prone to fatigue during use and the amount of force exerted by them will be reduced and this process will be intensified in the oral cavity environment.

This is an open access article distributed under the terms of the Creative Commons Attribution-NonCommercial-ShareAlike 3.0 License, which allows others to remix, tweak, and build upon the work non-commercially, as long as the author is credited and the new creations are licensed under the identical terms.

For reprints contact: reprints@medknow.com

How to cite this article: Behnaz M, Dalaie K, Hosseinpour S, Namvar F, Kazemi $\mathrm{L}$. The effect of toothpastes with bleaching agents on the force decay of elastomeric orthodontic chains. Eur J Dent 2017;11:427-31.

DOI: 10.4103/ejd.ejd_83_17 
${ }^{[7,8]}$ Another disadvantage of these chains is their susceptibility to oral cavity changes that could lead to permanent transformation of the chains. ${ }^{[9]}$ Therefore, to exert optimal forces and achieving the desired tooth movement in the shortest possible time, the dentist's awareness about the force exertion procedure by elastomeric chains and its decay process over time is essential. ${ }^{[10,11]}$ Numerous laboratory studies have examined the effect of various $\mathrm{pH}$ (acidic or neutral) values, ${ }^{[12,13]}$ temperature, ${ }^{[14]}$ different formulations of artificial saliva, ${ }^{[7]}$ different concentrations of alcohol in mouthwash, ${ }^{[15]}$ and the presence or absence of whitening ingredients in mouthwash ${ }^{[16]}$ on force decay of orthodontic elastomeric chains. Use of elastomeric chain due to its numerous benefits is common. The main weakness is rapid reduction in force values of elastomeric chains. Different studies have stated that several factors can cause force decay of chains..$^{[7-8]}$ Due to the increasing patients' demand for having whiter teeth, one of the goals of manufacturing companies is increasing toothpastes' cleaning and whitening effects. ${ }^{[17]}$ The components of toothpastes may influence the force of elastomeric chains and as a result can lead to insufficient tooth movement. According to our knowledge to date, the effect of whitening agents of toothpastes on the reduction of elastomeric chains force has not been studied yet and only the factors that directly affect the teeth have been assessed..$^{[16,18,19]}$ Thereby, the aim of this study was to evaluate the impact of agents in whitening toothpastes on the force of elastomeric chains used in orthodontics.

\section{MATERIALS AND METHODS}

In this prospective, experimental study, a total of 300 pieces of elastomeric chain were assessed. In this study, Bobbin chain gray (3M Unitek, USA457, AlastiK ${ }^{\mathrm{TM}}$ ) along with four types of toothpastes which were divided into five groups including four experimental and one control group was used [Table 1]. Experimental groups were as follows: group 1: regular Crest $^{\circledR}$ toothpaste and distilled water solution $(n=10$ for each time point); Group 2: whitening Crest ${ }^{\circledast}$ toothpaste and distilled water solution ( $n=10$ for each time point); Group 3: regular Sensodyne ${ }^{\circledR}$ toothpaste and distilled water solution ( $n=10$ for each time point); Group 4: whitening Sensodyne ${ }^{\circledR}$ toothpaste and distilled water solution ( $n=10$ for each time point); and (5) distilled water as a control group ( $n=10$ for each time point). Elastomeric chains were kept in a sealed bag (company packaging) at the proper temperature until the start of the experiment. ${ }^{[20]}$ The chains were cut identical to the pieces with 6 ring length and then the 300 pieces of elastomeric chains were divided into five aforementioned groups. In each group, two chain rings remain free in the middle and two rings were used to install the samples on jig. An additional free chain was considered to remove possible damages incurred during cutting and also for ease of doing the procedure. A total of six chain rings for the process were cut by a sharp cutter. Each piece of the elastomer was pulled to the ends of the jigs which are made of the polyvinyl chloride (PVC) pipes with the embedded small holes on either side of the pipe to put the supportive pins of elastomeric chains. The diameter of each pin was considered based on the standard bracket width, and length of each pin was considered $20 \mathrm{~mm} \cdot{ }^{[21]}$ Autopolymerizing acrylic resin was injected into the hole for fixing the pins. Each series of pins with a distance of $25 \mathrm{~mm}$ apart (proportional to the distance between middle point of canine to the middle point of first upper molar teeth), at opposite ends of PVC pipe, was placed to hold the elastomeric chains under tension in a fixed length (4 rings). ${ }^{[22,23]}$ This jigs allowed

\begin{tabular}{|c|c|c|}
\hline Group & Components & Composition \\
\hline 1 & Crest $^{\circledR}$ anticavity (Procter and Gamble, Germany) & $\begin{array}{l}\text { Sodium fluoride (1450 ppm 0.321\%), hydrated silica, sodium lauryl } \\
\text { sulfate, sodium saccharin, aqua, sorbitol, cellulose gum, aroma, } \\
\text { carbomer, limonene, Cl74160, Cl77891, trisodium phosphate }\end{array}$ \\
\hline 2 & Crest $^{\circledR}$ 3D whitening (Procter and Gamble, Germany) & $\begin{array}{l}\text { Sodium fluoride ( } 1450 \mathrm{ppm} 0.321 \% \text { ), hydrated silica, sodium lauryl sulfate, } \\
\text { sodium saccharin, xanthan gum, aqua, sorbitol, disodium pyrophosphate, } \\
\text { cellulose gum, aroma, sodium hydroxide, carbomer, limonene, Cl } 74160\end{array}$ \\
\hline 3 & Sensodyne ${ }^{\circledR}$ (Neocosmed Co., Ltd., Thailand) & $\begin{array}{l}\text { Sodium fluoride } 0.221 \% \mathrm{w} / \mathrm{w} \text {, potassium nitrate } 5.00 \% \mathrm{w} / \mathrm{w} \text {, glycerin, } \\
\text { hydrated silica, sodium hydroxide, sodium saccharin, titanium dioxide, } \\
\text { water, sorbitol, cocamidopropyl betaine, xanthan gum, flavor, sucralose }\end{array}$ \\
\hline 4 & Sensodyne ${ }^{\circledR}$ gentle whitening (Neocosmed. Thailand) & $\begin{array}{l}\text { Sodium fluoride } 0.221 \% \mathrm{w} / \mathrm{w} \text {, potassium nitrate } 5.00 \% \mathrm{w} / \mathrm{w} \text {, pentasodium } \\
\text { triphosphate } 5.00 \% \mathrm{w} / \mathrm{w} \text {, glycerin, hydrated silica, PEG- } 6 \text {, sodium hydroxide, } \\
\text { sodium saccharin, titanium dioxide, water, sorbitol, cocamidopropyl } \\
\text { betaine, sodium methyl cocoyl taurate, xanthan gum, flavor }\end{array}$ \\
\hline 5 & Distilled water & - \\
\hline
\end{tabular}


complete immersion of chains in a container containing distilled water or the solution provided throughout the study period. Throughout the duration of the study, samples of the control group were kept in distilled water and samples of the experimental groups, each independently, were immersed in solutions containing distilled water and toothpaste once a day for $2 \mathrm{~min}$. Control and experimental groups' samples were kept in incubator $\left(37^{\circ} \mathrm{C}\right)$. The samples' force was recorded in universal mechanical testing machine (Instron) before, $1,7,14$, and 28 days after the intervention for all groups.

All data were analyzed using SPSS 20.0.1 (IBM Corp., Armonk, NY, USA) for Windows software. The normal distribution of elastic force was examined using the Kolmogorov-Smirnov test between five groups and at six time points. Two-way ANOVA test was used to evaluate the effects of toothpaste type and the exposure time on mean force of elastomeric chains. In case that there was an interaction between different kinds of toothpaste and the exposure times, Bonferroni method was used to compare the $2 \times 2$ effects of toothpastes at any time.

\section{RESULTS}

Figure 1 shows the gradual reduction of forces from the start point to $28^{\text {th }}$ day. At the initial time point, there was no significant difference among different groups $(P>0.05)$. One day after intervention, a significant difference $(P<0.05)$ was observed in all groups except between the Groups 2 with $4(P=0.54)$ or with Group $3(P=0.063)$. On days 7,14 , and 28 after intervention, the rate of decline in all groups was statistically significant $(P<0.05)$. The decline in the force decay of elastomeric chains $(\mathrm{N})$ has been shown in Table 2. By the end of the 28-day period, the highest reduction was observed in Group 4 (95.90\%) and the lowest reduction after the control group $(50.11 \%)$ was observed in Group 1 (74.56\%).

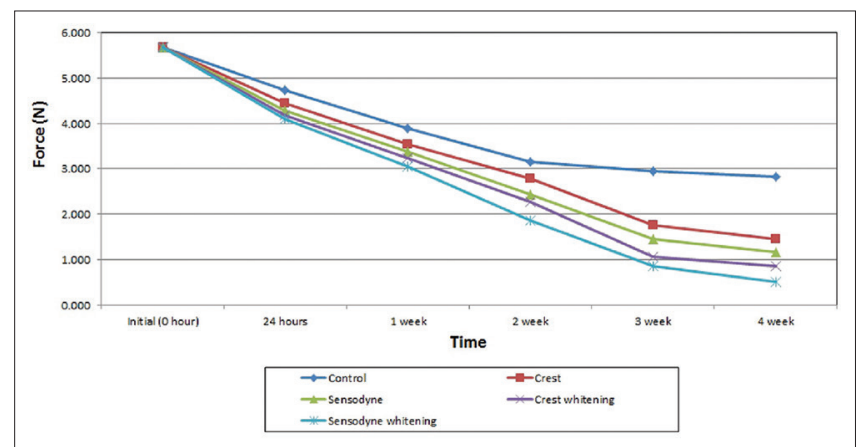

Figure 1: The gradual reduction of forces from the start point to the $28^{\text {th }}$ day

\section{DISCUSSION}

Orthodontic elastics are widely used in orthodontic treatment for force transmission. As these devices are not ideal due to the gradual erosive forces during operations, ${ }^{[24]}$ several studies have been carried out on the mechanical effects of environmental factors on the loss of chains' forces. ${ }^{[25,26]}$ Due to the increasing use of whitening toothpastes by patients for various reasons, the study of these factors on the force of such orthodontic appliances is necessary. In this study, the effect of toothpastes containing bleaching agents on elastomeric chain force was assessed. The results showed that $\mathrm{Crest}^{\circledR}$ had the least and the Sensodyne ${ }^{\circledR}$ containing bleach had the highest effect on force decay. In vitro design has several advantages for evaluation of material characterizations. Standardization of the oral cavity environment is difficult. Differences in microbial flora and enzyme levels along with dietary factors and different functional forces undermine the validity of material properties' assessments. ${ }^{[7]}$ Although the in vitro researches are valuable, direct generalization of the results to clinical situations should be taken with caution. One of the main limitations in analyzing the results of this study was the lack of similar in vivo studies. Ash and Nikolai showed that the loss of elastomeric chains force in the laboratory (in vitro) condition was lower compared to that of oral cavity environment (in vivo). ${ }^{[27]}$ In a study by Rock et al., it was also indicated that only $43 \%-52 \%$ of the initial force in elastomeric chains was maintained in oral cavity environment after 4 weeks while the chains which were kept in the air maintained $70 \%-75 \%$ of their initial force. ${ }^{[28]}$ Several studies have shown a considerable difference between dry and in vivo environments while the difference between various aqueous and in vivo environments was not significant. ${ }^{[27,29]}$ The researchers have investigated the effect of temperature variations in reducing the force of elastomeric orthodontic chains and have declared that these chains are very sensitive to changes in temperature. ${ }^{[4,27,30]}$ In a study by Nattrass et al., the force decay in chains was evaluated at different temperature conditions $\left(10^{\circ} \mathrm{C}\right.$, $22^{\circ} \mathrm{C}$, and $37^{\circ} \mathrm{C}$ ) and the results showed that overall chains' force reduction exceeded by increasing the temperature. ${ }^{[31]}$ Regarding the fact that there was no study on the effect of different toothpastes on force decay of immersed chains, this study was carried out for the first time and the results revealed that toothpastes containing bleaching agents have adverse effects on the elastomeric chains. 
Behnaz, et al.: Bleaching agents and elastomeric orthodontic chain force

\begin{tabular}{|c|c|c|c|c|}
\hline Type & Time point & Mean force $(n)$ & Percentage of decay & SD \\
\hline \multirow[t]{6}{*}{ Control } & Initial & 5.66 & - & 0.086 \\
\hline & $24 \mathrm{~h}$ & 4.73 & 16.47 & 0.089 \\
\hline & 1 week & 3.88 & 31.41 & 0.064 \\
\hline & 2 weeks & 3.14 & 44.53 & 0.094 \\
\hline & 3 weeks & 2.94 & 48.01 & 0.082 \\
\hline & 4 weeks & 2.82 & 50.11 & 0.089 \\
\hline \multirow[t]{6}{*}{ Crest $^{\circledR}$ anticavity (Procter and Gamble, Germany) } & Initial & 5.66 & - & 0.086 \\
\hline & $24 \mathrm{~h}$ & 4.44 & 21.58 & 0.101 \\
\hline & 1 week & 3.53 & 37.58 & 0.086 \\
\hline & 2 weeks & 2.77 & 51.01 & 0.076 \\
\hline & 3 weeks & 1.75 & 69.03 & 0.083 \\
\hline & 4 weeks & 1.44 & 74.56 & 0.065 \\
\hline \multirow[t]{6}{*}{ Sensodyne ${ }^{\circledR}$ (Neocosmed. Thailand) } & Initial & 5.66 & - & 0.086 \\
\hline & $24 \mathrm{~h}$ & 4.27 & 24.60 & 0.081 \\
\hline & 1 week & 3.37 & 40.54 & 0.097 \\
\hline & 2 weeks & 2.43 & 56.98 & 0.087 \\
\hline & 3 weeks & 1.45 & 74.37 & 0.099 \\
\hline & 4 weeks & 1.15 & 79.54 & 0.102 \\
\hline \multirow[t]{6}{*}{ Crest $^{\circledR}$ 3D whitening (Procter and Gamble, Germany) } & Initial & 5.66 & - & 0.086 \\
\hline & $24 \mathrm{~h}$ & 4.16 & 26.48 & 0.099 \\
\hline & 1 week & 3.22 & 3.06 & 0.065 \\
\hline & 2 weeks & 2.27 & 59.85 & 0.086 \\
\hline & 3 weeks & 1.06 & 81.26 & 0.119 \\
\hline & 4 weeks & 0.84 & 85.04 & 0.095 \\
\hline \multirow[t]{6}{*}{ Sensodyne ${ }^{\circledR}$ gentle whitening (Neocosmed. Thailand) } & Initial & 5.66 & - & 0.086 \\
\hline & $24 \mathrm{~h}$ & 4.09 & 27.80 & 0.050 \\
\hline & 1 week & 3.05 & 46.08 & 0.088 \\
\hline & 2 weeks & 1.85 & 67.28 & 0.087 \\
\hline & 3 weeks & 0.86 & 84.80 & 0.076 \\
\hline & 4 weeks & 0.51 & 90.95 & 0.048 \\
\hline
\end{tabular}

\section{CONCLUSIONS}

Considering the results of this study, it seems that the regular toothpastes have less adverse effect on elastomeric chains compared to the whitening toothpastes and that the regular Crest ${ }^{\circledR}$ toothpaste showed the least impact on force decay of elastomeric chains in comparison to both the Sensodyne ${ }^{\circledR}$ toothpastes.

\section{Financial support and sponsorship \\ Nil.}

\section{Conflicts of interest}

There are no conflicts of interest.

\section{REFERENCES}

1. Shetty S, Maurya R, Raj H, Patil A. Comparison of the pendulum appliance and the Jones jig: A prospective comparative study. Eur J Dent 2017;11:323-9.

2. Kecik D. Comparison of temporary anchorage devices and transpalatal arch-mediated anchorage reinforcement during canine retraction. Eur
J Dent 2016;10:512-6.

3. Mirhashemi A, Saffarshahroudi A, Sodagar A, Atai M. Force-degradation pattern of six different orthodontic elastomeric chains. J Dent (Tehran) 2012;9:204-15.

4. von Fraunhofer JA, Coffelt MT, Orbell GM. The effects of artificial saliva and topical fluoride treatments on the degradation of the elastic properties of orthodontic chains. Angle Orthod 1992;62:265-74.

5. Brantley WA, Eliades T. Orthodontic materials: scientific and clinical aspects. Stuttgart: Thieme; 2001.

6. Baty DL, Volz JE, von Fraunhofer JA. Force delivery properties of colored elastomeric modules. Am J Orthod Dentofacial Orthop 1994;106:40-6.

7. Eliades T, Eliades G, Silikas N, Watts DC. In vitro degradation of polyurethane orthodontic elastomeric modules. J Oral Rehabil 2005;32:72-7.

8. Fernandes DJ, Fernandes GM, Artese F, Elias CN, Mendes AM. Force extension relaxation of medium force orthodontic latex elastics. Angle Orthod 2011;81:812-9.

9. Bousquet JA Jr., Tuesta O, Flores-Mir C. In vivo comparison of force decay between injection molded and die-cut stamped elastomers. Am J Orthod Dentofacial Orthop 2006;129:384-9.

10. Russell KA, Milne AD, Khanna RA, Lee JM. In vitro assessment of the mechanical properties of latex and non-latex orthodontic elastics. Am J Orthod Dentofacial Orthop 2001;120:36-44.

11. Kanchana P, Godfrey K. Calibration of force extension and force degradation characteristics of orthodontic latex elastics. Am J Orthod Dentofacial Orthop 2000;118:280-7.

12. Lacerda Dos Santos R, Pithon MM, Romanos MT. The influence of $\mathrm{pH}$ levels on mechanical and biological properties of nonlatex and latex elastics. Angle Orthod 2012;82:709-14. 


\section{Behnaz and Hosseinpour: Bleaching agents and elastomeric orthodontic chain force}

13. Sauget PS, Stewart KT, Katona TR. The effect of $\mathrm{pH}$ levels on nonlatex vs. Latex interarch elastics. Angle Orthod 2011;81:1070-4.

14. Paige SZ, Tran AM, English JD, Powers JM. The effect of temperature on latex and non-latex orthodontic elastics. Tex Dent J 2008;125:244-9.

15. Larrabee TM, Liu SS, Torres-Gorena A, Soto-Rojas A, Eckert GJ, Stewart KT, et al. The effects of varying alcohol concentrations commonly found in mouth rinses on the force decay of elastomeric chain. Angle Orthod 2012;82:894-9.

16. da Rosa GM, da Silva LM, de Menezes M, do Vale HF, Regalado DF, Pontes DG, et al. Effect of whitening dentifrices on the surface roughness of a nanohybrid composite resin. Eur J Dent 2016;10:170-5.

17. Pithon MM, Rodrigues AC, Sousa EL, Santos LP, Soares Ndos S. Do mouthwashes with and without bleaching agents degrade the force of elastomeric chains? Angle Orthod 2013;83:712-7.

18. Franzò D, Philpotts CJ, Cox TF, Joiner A. The effect of toothpaste concentration on enamel and dentine wear in vitro. J Dent 2010;38:974-9.

19. Smith BG, Knight JK. A comparison of patterns of tooth wear with aetiological factors. Br Dent J 1984;157:16-9.

20. Addy M, Hunter ML. Can tooth brushing damage your health? Effects on oral and dental tissues. Int Dent J 2003;53 Suppl 3:177-86.

21. Ramezanzadeh B, Hasan ZN, Eslami N, Dehghani M, Esmaeili H. Evaluation of the Effect of Sodium Fluoride Mouth Rinse Application on the Elastic Properties of Elastomeric Chains; 2008.

22. Fattahi H, Poursayah A. The effect of prestretching on force degradation of synthetic elastomeric chains. J Dent Shiraz Univ Med
Sci 2011;12:26-33.

23. Kumar K, Shetty S, Krithika MJ, Cyriac B. Effect of commonly used beverage, soft drink, and mouthwash on force delivered by elastomeric chain: A comparative in vitro study. J Int Oral Health 2014;6:7-10.

24. Balhoff DA, Shuldberg M, Hagan JL, Ballard RW, Armbruster PC. Force decay of elastomeric chains - A mechanical design and product comparison study. J Orthod 2011;38:40-7.

25. Oshagh M, Khajeh F, Heidari S, Torkan S, Fattahi HR. The effect of different environmental factors on force degradation of three common systems of orthodontic space closure. Dent Res J (Isfahan) 2015;12:50-6.

26. Weissheimer A, Locks A, de Menezes LM, Borgatto AF, Derech CD. In vitro evaluation of force degradation of elastomeric chains used in orthodontics. Dental Press J Orthod 2013;18:55-62.

27. Ash JL, Nikolai RJ. Relaxation of orthodontic elastomeric chains and modules in vitro and in vivo. J Dent Res 1978;57:685-90.

28. Rock WP, Wilson HJ, Fisher SE. A laboratory investigation of orthodontic elastomeric chains. Br J Orthod 1985;12:202-7.

29. Kuster R, Ingervall B, Bürgin W. Laboratory and intra-oral tests of the degradation of elastic chains. Eur J Orthod 1986;8:202-8.

30. Stevenson JS, Kusy RP. Force application and decay characteristics of untreated and treated polyurethane elastomeric chains. Angle Orthod 1994;64:455-64.

31. Nattrass C, Ireland AJ, Sherriff M. The effect of environmental factors on elastomeric chain and nickel titanium coil springs. Eur J Orthod 1998;20:169-76. 